\title{
A Study of Geotechnical Properties of Silty Soil Blended With Used Foundry Sand
}

\author{
Nitin Kumar Singh ${ }^{1}$, Bipin Prajapati ${ }^{2}$ \\ ${ }^{1}$ P.G. Scholar, Civil Engineering Department, KNIT Sultanpur, U.P, INDIA \\ ${ }^{2}$ Assistant Professor, , Civil Engineering Department, KNIT Sultanpur, U.P, INDIA
}

\begin{abstract}
This paper depicts the consequences of research facility examination directed to assess the effect on sub-grade qualities of silty soil mixed with foundry sand. Foundry sand is a waste materials acquired from various commercial enterprises forcing perilous impact on environment and human wellbeing. In spite of the fact that usage of foundry sand is keeping on developing, yet at the same time there is considerable amount that remaining parts unutilized. The natural properties of foundry sand can be utilized to get a compelling sub-grade material with blend soil and the issues of their transfer can be fathomed to some degree. The outcomes demonstrate that with expansion of foundry sand to soil, its quality and compaction attributes are moved forward.
\end{abstract}

Keywords: Silty soil, foundry sand, strength, compaction, sub-grade

\section{Introduction}

A foundry is an assembling office that produces metal castings by emptying liquid metal into a preformed mold to yield the subsequent solidified cast. The essential metals cast incorporate iron and steel from the ferrous family and aluminum, copper, metal and bronze from the nonferrous family. Foundry sand is fantastic silica sand that is a by-item from the generation of both ferrous and nonferrous metal castings. The physical and concoction qualities of foundry sand will depend in incredible part on the sort of throwing procedure and the business division from which it starts. Metal foundries utilize a lot of sand as a component of the metal throwing process. Foundries effectively reuse and reuse the sand commonly in a foundry. At the point when sand can never again be reused in the foundry, it is expelled from the foundry and is termed "foundry sand." Foundry sand creation is about 6 to 10 million tons yearly. In the same way as other waste items, foundry sand has gainful applications to different commercial ventures. Foundries buy top notch size-particular silica sands for use in their embellishment and throwing operations. The crude sand is regularly of a higher quality than the average bank run or common sands utilized as a part of fill development destinations. The sands frame the external state of the mold depression. These sands regularly depend upon a little measure of betonies earth to go about as the cover material. Compound covers are likewise used to make sand "centers". There are two essential sorts of foundry sand accessible, green sand (frequently alluded to as embellishment sand) that utilizations dirt as the cover material, and artificially reinforced sand that utilizations polymers to tie the sand grains together. Green sand comprises of $85-95 \%$ silica, 0$12 \%$ earth, 2-10\% carbonaceous added substances, for example, ocean coal, and 2-5\% water. Green sand is the most usually utilized embellishment media by foundries. The silica sand is the mass medium that opposes high temperatures while the covering of earth ties the sand together. The water includes versatility. The carbonaceous added substances keep the "smolder on" or combining of sand onto the throwing surface. Green sands additionally contain follow chemicals, for example, $\mathrm{MgO}, \mathrm{K} 2 \mathrm{O}$, and
TiO2. Artificially fortified sand comprises of $93-99 \%$ silica and $1-3 \%$ compound fastener. Silica sand is altogether blended with the chemicals; an impetus starts the response that cures and solidifies the mass. There are different compound fastener frameworks utilized as a part of the foundry industry. The most common chemical binder systems used are phenol-urethanes, epoxy-resins, fury alcohol, and sodium silicates.

\section{Experimental Program}

\subsection{Material used}

The soil taken in this study is from Kunda, Pratapgarh, Uttar Pradesh which is silty in nature and the foundry sand used is made available from V.P.G. Enterprises at Jamshedpur, West Bengal, INDIA working for TISCON.

Table 1: Physical properties of foundry sand:

\begin{tabular}{|l|c|c|}
\hline S. No & Physicalproperties & Foundry Sand \\
\hline 1. & Specific gravity & 2.56 \\
\hline 2. & Maximum dry density & $1 . .573$ \\
\hline 3. & Optimum moisture content (OMC), (\%) & 6.0 \\
\hline 4. & Liquid limit (\%) & - \\
\hline 5. & Plastic limit (\%) & - \\
\hline 6. & Plasticity index (\%) & - \\
\hline 7. & Soaked CBR (\%) & 9.77 \\
\hline
\end{tabular}

\subsection{Testing Method}

Following are the tests which are performed on soil mixed with foundry sand in the ratio of 100:0, 95:5, 90:10, 85:15, $80: 20,75: 25$, and 70:30 respectively.

1. Particle size distribution

2. Liquid limit \& Plastic limit

3. Hydrometer

4. California bearing ratio (CBR)

5. OMC \& MDD 


\section{International Journal of Science and Research (IJSR) \\ ISSN (Online): 2319-7064}

Index Copernicus Value (2013): 6.14 | Impact Factor (2015): 6.391

\section{Particle size distribution}

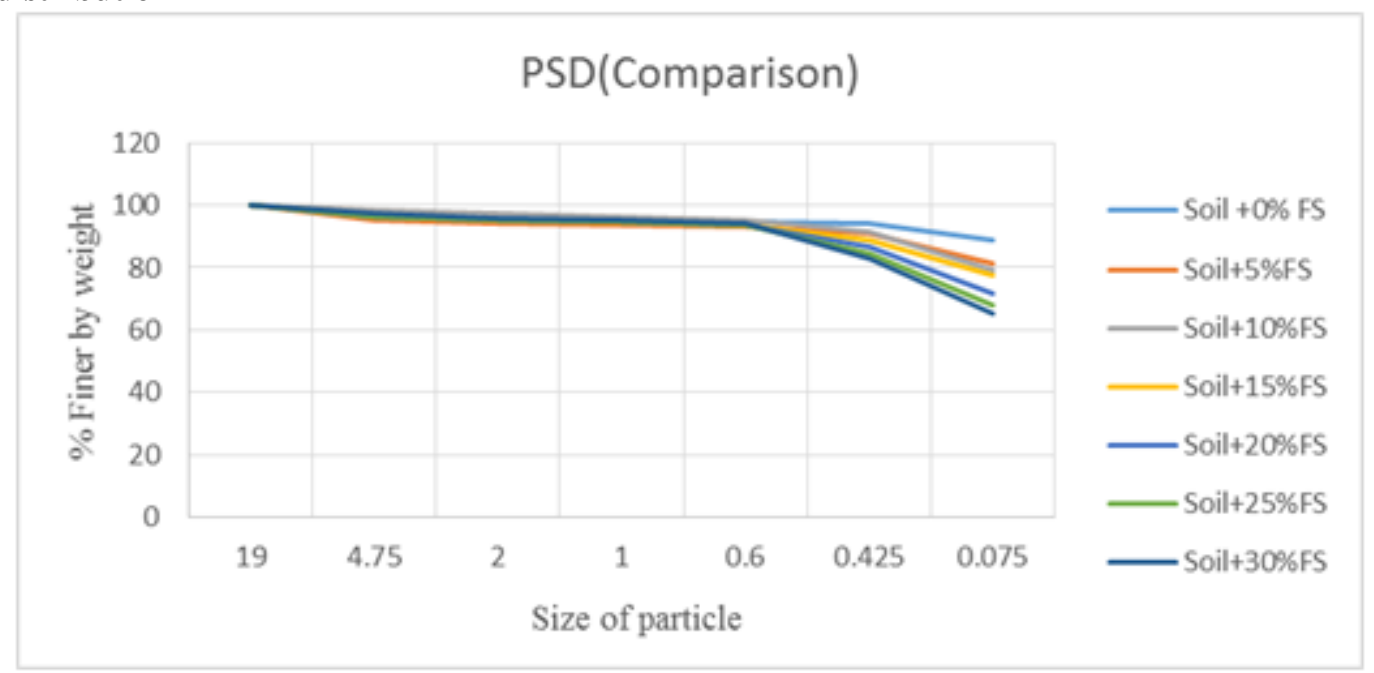

Figure 1: Particle size distribution of soil mixed with foundry sand

\section{OMC \& MDD:}

The water content-dry density of silty soil blended with foundry sand content fluctuating from 5\% to $30 \%$ are appeared in figure 2. It is watched that greatest maximum density (MDD) of sediment foundry sand composite increments with the expansion in foundry sand content up to
$20 \%$ after which it is diminished. This happens because of the reason that the void spaces between the sand particles are possessed by the dirt particles up to a specific rate from that point the additional sand substance isolates the particles which has a tendency to diminish the density.

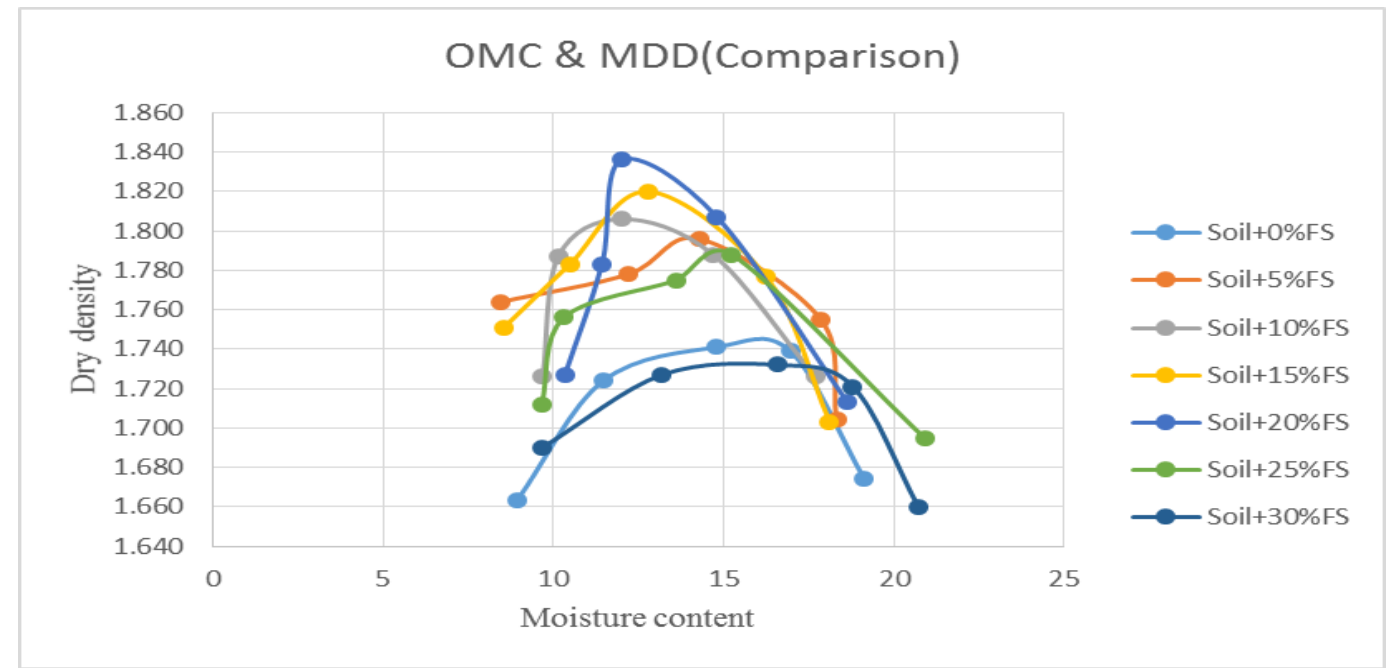

Figure 2: Compaction characteristics of soil-foundry sand mixes

CBR:

The aftereffects of California bearing proportion (CBR) tests on silty soil treated with foundry sand are appeared in figure 3. It is watched that CBR estimation of silty soil diminished with expansion of foundry sand. The estimation of CBR declines from $4.57 \%$ for un-settled soil to $5.21 \%$ for balanced out soil. The change in CBR quality might be credited to better compaction and pressing of the blend particles with expansion of foundry sand. 


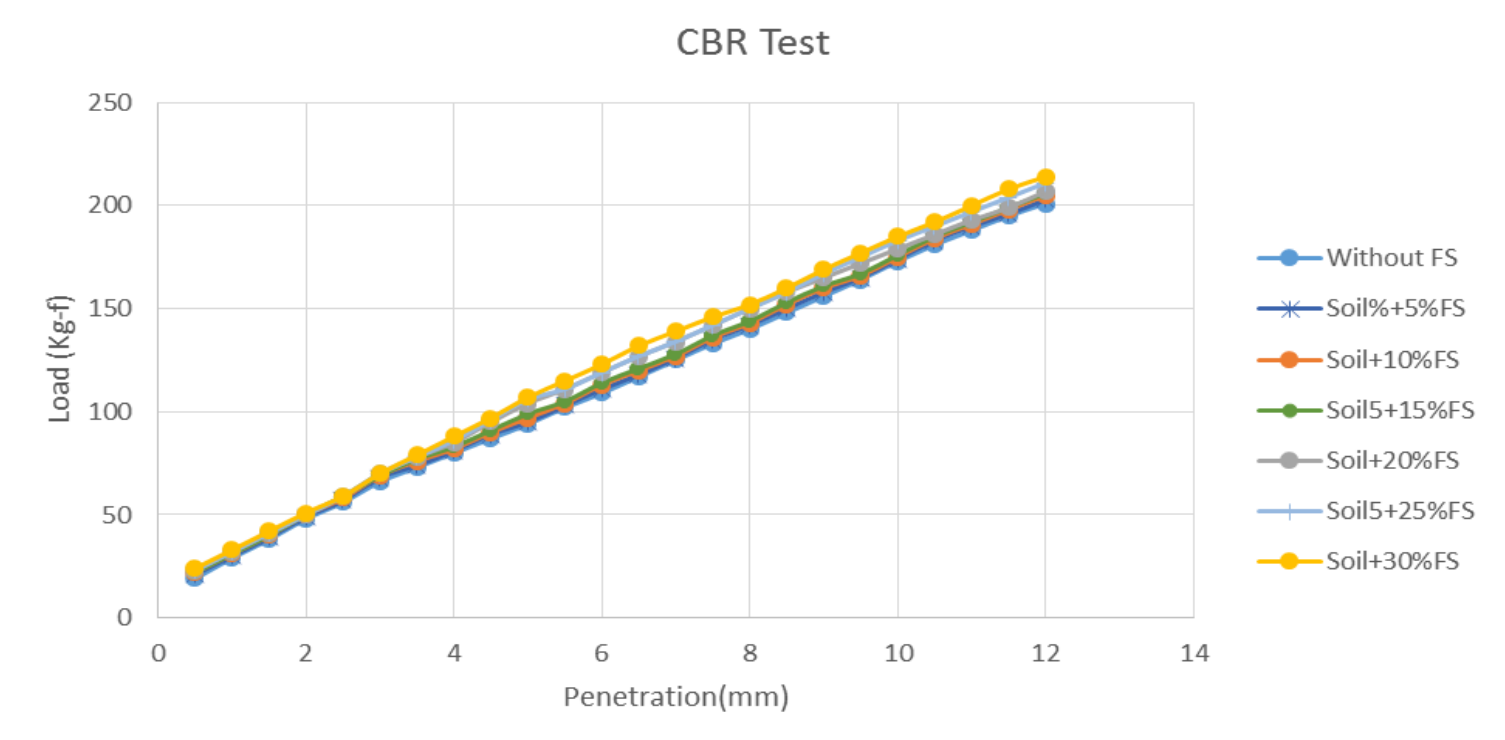

Figure 3: Variation of CBR value with optimum mix

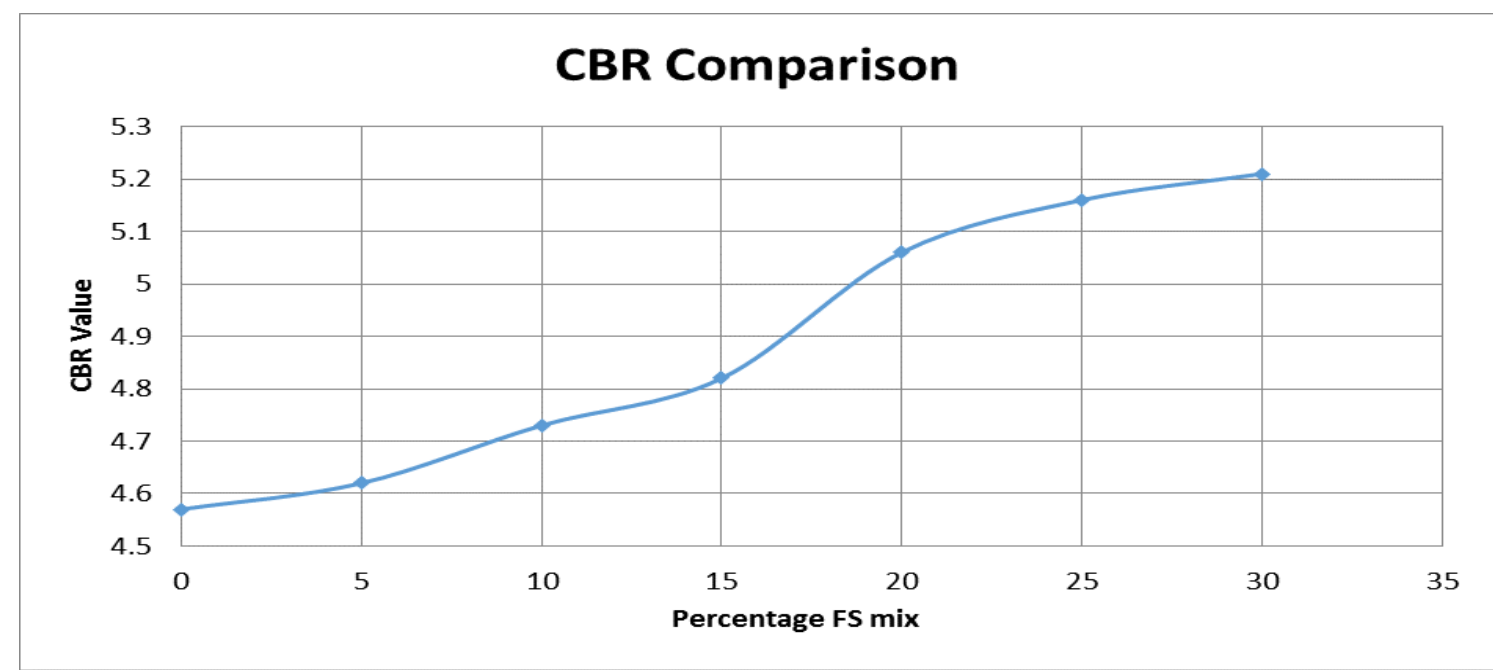

Figure 4: Comparison of CBR value of soil mixed with foundry sand

\section{Liquid Limit \& Plastic Limit:}

\section{Comparison of LL \& PL}

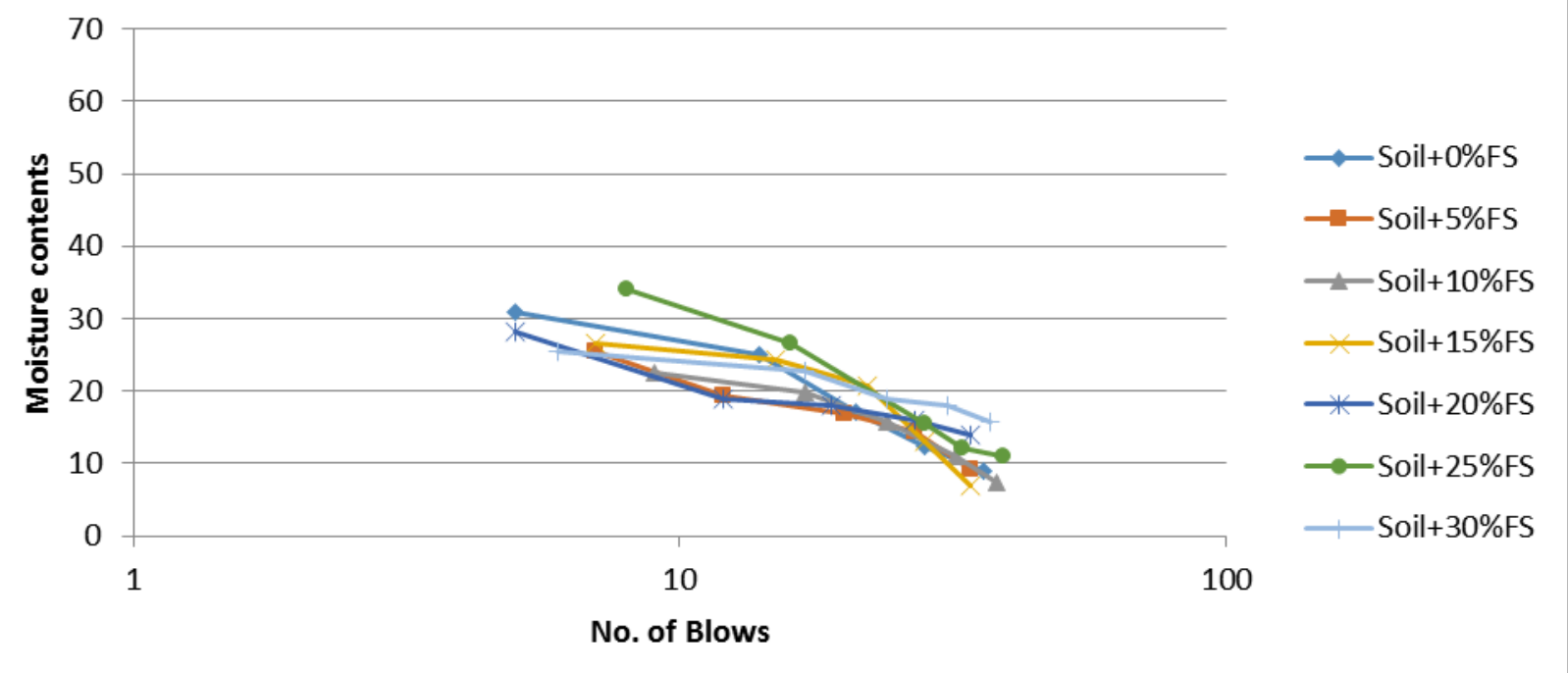

Figure 5: Variation of liquid \& plastic limit with different foundry sand mixes

\section{Volume 5 Issue 6, June 2016} www.ijsr.net

Licensed Under Creative Commons Attribution CC BY 


\section{International Journal of Science and Research (IJSR)}

ISSN (Online): 2319-7064

Index Copernicus Value (2013): 6.14 | Impact Factor (2015): 6.391

\section{Hydrometer}

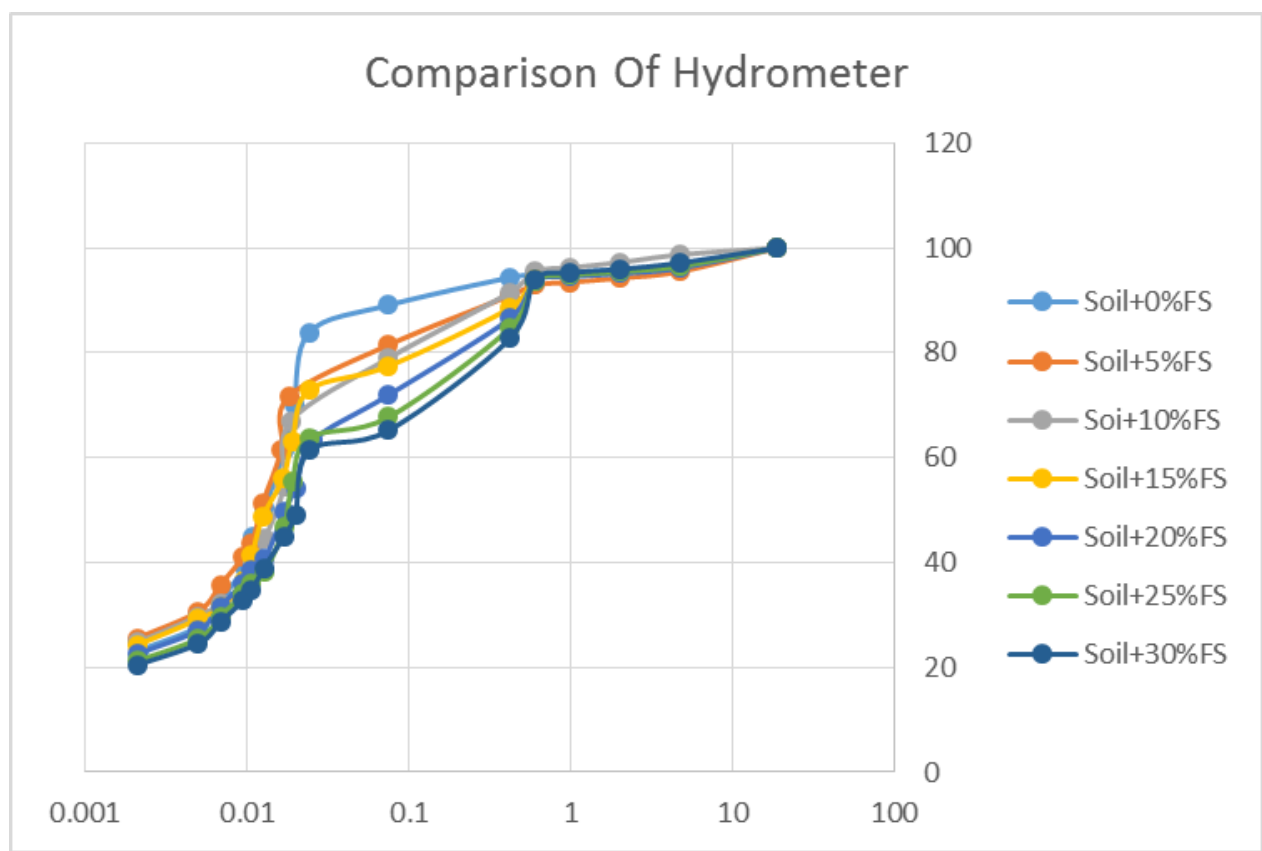

Figure 6: Hydrometer comparison of soil mixed with foundry sand

\section{Comparative Study of Results}

\begin{tabular}{|c|c|c|c|c|c|c|c|c|}
\hline \multicolumn{9}{|c|}{ Location: Soil near Kunda, Pratapgarh, Uttar Pradesh , INDIA } \\
\hline Properties & & $\mathbf{1 0 0 \%}$ Soi & $\begin{array}{c}\mathbf{9 5 \%} \text { Soil + } \\
\mathbf{5 \%} \text { UFS }\end{array}$ & $\begin{array}{c}\mathbf{9 0 \%} \text { Soil + } \\
\mathbf{1 0 \%} \text { UFS }\end{array}$ & $\begin{array}{c}\mathbf{8 5 \%} \text { Soil + } \\
\mathbf{1 5 \%} \text { UFS }\end{array}$ & $\begin{array}{c}\mathbf{8 0 \%} \text { Soil + } \\
\mathbf{2 0 \%} \text { UFS }\end{array}$ & $\begin{array}{c}\mathbf{7 5 \%} \text { Soil + } \\
\mathbf{2 5 \%} \text { UFS }\end{array}$ & $\begin{array}{c}\mathbf{7 0 \%} \text { Soil + 30\% } \\
\text { UFS }\end{array}$ \\
\hline GSD & & & & & & & & \\
\hline & Gravel & $3.15 \%$ & $4.52 \%$ & $1.30 \%$ & $3.24 \%$ & $3.85 \%$ & $3.50 \%$ & $2.97 \%$ \\
\hline & Sand & $7.78 \%$ & $14.01 \%$ & $19.76 \%$ & $19.33 \%$ & $24.23 \%$ & $28.81 \%$ & $31.98 \%$ \\
\hline LL & & 15 & 14 & 14 & 13 & 12 & 12 & 11 \\
\hline PL & & 13.53 & 13.29 & 12.87 & 12.16 & 11.59 & 11.06 & 10.51 \\
\hline PI & & 1.47 & 0.71 & 1.13 & 0.84 & 0.41 & 0.94 & 0.49 \\
\hline Classification & ML & & & & & & & 1.94 \\
\hline OMC & & 14.79 & 14.29 & 12.00 & 11.98 & 12.01 & 15.24 & 16.60 \\
\hline MDD & & 1.741 & 1.796 & 1.806 & 1.820 & 1.836 & 1.788 & 1.732 \\
\hline CBR & & 4.57 & 4.62 & 4.73 & 4.82 & 5.06 & 5.16 & 5.21 \\
\hline
\end{tabular}

\section{Conclusion}

1) The most noteworthy estimation of maximum dry density is accomplished for soil-foundry sand blend of 80:20 took after by different extents (Figure 2). This happens because of the reason that the voids between the foundry sand particles are involved by the dirt particles when the sand substance is less however bigger sand content isolates the particles and the most extreme dry thickness diminishes.

2) The ideal dampness substance of silty soil foundry sand blend diminished with the expansion of foundry sand (up to $15 \%$ substance) though it expanded a short time later (Figure 2). This happens because of lower amount of water required to grease up the foundry sand particles which are coarser contrasted and earth particles.

3) The California bearing proportion estimation of silty soil increases fundamentally i.e. from $4.57 \%$ to $5.21 \%$ with expansion of foundry sand (Figure 3 ).
4) Thus, silty soil settled with foundry sand can be utilized as a sub-level material for development of adaptable asphalts in rustic streets with low movement volume.

\section{References}

[1] Kenneth. A., Hegazy, Y., and Jasperse, B. (2001) Adjustment of Delicate Soils by Soil Blending. Delicate Ground Innovation: pp. 194-205. doi: 10.1061/40552(301)16.

[2] ASTM D422-63, "Standard test strategies for hydro meter investigation of soils," American Culture for Testing of Materials, Pennsylvania, Dad, USA.

[3] ASTM D698-07e1, "Standard test strategies for research center compaction qualities of soil utilizing standard exertion," American Culture for Testing of Materials, Pennsylvania, Dad, USA.

[4] ASTM D854-10, "Standard test strategies for particular gravity of soil," American Culture for Testing of Materials, Pennsylvania, Dad, USA.

Volume 5 Issue 6, June 2016 www.ijsr.net 


\section{International Journal of Science and Research (IJSR) \\ ISSN (Online): 2319-7064}

Index Copernicus Value (2013): 6.14 | Impact Factor (2015): 6.391

[5] ASTM D1883-05, "Standard test strategies for California bearing proportion test for soils," American Culture for Testing of Materials, Pennsylvania, Dad, USA.

[6] ASTM D2487-11, "Standard practice for order of soils for building purposes (bound together soil arrangement framework)," American Culture for Testing of Materials, Pennsylvania, Dad, USA.

[7] ASTM D4318-10, "Standard test techniques for fluid cutoff, plastic point of confinement, and pliancy file of soils," American Culture for Testing of Materials, Pennsylvania, Dad, USA.

[8] ASTM D5239-2004, "Standard practice for describing fly fiery remains for use in soil adjustment," American Culture for Testing of Materials, West Conshohocken, Dad, USA.

[9] ASTM D6913-04, "standard test strategies for molecule size dispersion of soils," American Culture for Testing of Materials, Pennsylvania, Dad, USA.

[10] Abichou T, Edil TB, Benson $\mathrm{CH}$, Bahia $\mathrm{H}$. Advantageous utilization of foundry by-items in expressway development. In: Geotechnical building for transportation ventures: Procedures of geo-trans 2004, Jul 27-31 2004. Los Angeles, CA, Joined States: American Culture of Structural Designers, Reston, VA 20191-4400, Joined States; 2004.

[11] Abichou, T., Benson, C.H., Edil, T.B., and Tawfiq, K., "Water powered Conductivity of Foundry Sands and Their utilization as Pressure driven Boundaries," In: Aydilek, A.H. and Wartman, J. (Eds.), Reused Materials in Geotechnics, Geotechnical Unique Distribution 127. ASCE, Baltimore, Maryland, 2004.

\section{Author Profile}

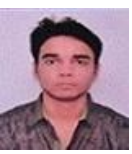

Nitin Kumar Singh received the B.tech degree in Civil Engineering in the year 2014 from Galgotias College of Engineering and Technology, Greater Noida, U.P. and currently pursuing M.tech in Geotechnical and Geo-environmental Engineering from Kamla Nehru Institute of Technology, Sultanpur, U.P.. 